\title{
Analisis Umur Mesin, Maintenance Crew, serta Total Money Lost menggunakan Metode Life Cycle Cost dan Cost of Unreliability pada Mesin Eurosicma E75 DS (4)/A
}

\section{Analysis of Retirement Age, Maintenance Crew, and Total of Money Lost using Life Cycle Cost of Unreliability at Eurosicma E75 DS (4)/A Machine}

\author{
Wefi Ridha Maryami*, Judi Alhilman, Nurdinintya Athari Supratman \\ Program Studi Teknik Industri, Fakultas Rekayasa Industri, Universitas Telkom
}

\section{INFO ARTIKEL}

\section{Article history:}

Diterima 24-02-2019

Diperbaiki 11-04-2019

Disetujui 12-05-2019

\section{Kata Kunci:}

Downtime, Maintenance Crew, Life Cycle Cost, Sustaining Cost, Acquisition Cost, Cost of Unreliability

\section{ABSTRAK}

PT XYZ adalah salah satu perusahaan yang memproduksi makanan, seperti permen. Proses produksi permen ini dilakukan dengan menggunakan mesin, salah satunya mesin Eurosicma E75 DS (4)/A yang digunakan untuk proses packaging. Berdasarkan data tahun 2017, mesin ini hanya mampu mencapai target availability selama satu bulan dan memiliki frekuensi downtime terbesar dibandingkan mesin lainnya, yaitu sebanyak 37 kali kerusakan. Hal ini dapat disebabkan oleh beberapa faktor, termasuk umur mesin yang sudah melampaui batas optimalnya, sehingga menyebabkan perusahaan perlu melakukan kegiatan maintenance untuk mengembalikan kinerja mesin yang maksimal. Dalam melakukan kegiatan maintenance, diperlukan untuk mengetahui jumlah maintenance crew. Untuk menentukan umur mesin dan jumlah maintenance crew yang optimal dapat digunakan metode Life Cycle Cost (LCC). Metode ini dihitung dari penjumlahan sustaining cost dan acquisition cost. Selain itu, untuk mengetahui besarnya kerugian atas ketidakandalan mesin dilakukan perhitungan dengan metode Cost of Unreliability (COUR) yang terdiri atas perhitungan failure rate, time lost, dan money lost. Berdasarkan perhitungan LCC, diperoleh total nilai LCC terkecil sebesar Rp1.451.140.737 dengan umur mesin optimal adalah delapan tahun dan jumlah maintenance crew optimal sebanyak tujuh orang. Berdasarkan hasil perhitungan COUR, diperoleh nilai corrective money lost sebesar Rp57.097.869.694 dan downtime money lost senilai Rp60.671.980.382. Kondisi ini menandakan mesin membutuhkan kebijakan perawatan yang lebih efisien.

ABSTRACT

PT XYZ is one of the companies that produce food, such as candy. This candy production process is done by using machine, one of Eurosicma E75 DS (4) / A machine used for packaging process. Based on data in 2017, this machine is only able to achieve target availability for one month and has the biggest downtime frequency compared to other machines, which is 37 times damage. This can be caused by several factors, including the age of the engine that has exceeded its optimal limit, causing the company to perform maintenance activities to restore maximum engine performance. In doing maintenance activities, it is necessary to know the number of maintenance crew. To determine the optimal age of the machine and the optimal number of maintenance crew can be used Life Cycle Cost (LCC) method. This method is calculated from the sum of sustaining cost and acquisition cost. In addition, to know the magnitude of lostes for the reliability of the machine is calculated by the method of Cost of Unreliability (COUR) which consists of the calculation of failure rate, time lost, and money lost. Based on the calculation of LCC, obtained the smallest LCC value of Rp1,451,140,737 with the retirement age is eight years and the optimal number of maintenance crew is seven people. Based on the calculation of COUR, obtained corrective money lost value of Rp57.097.869.694 and downtime money lost worth Rp60.671.980.382. This condition indicates the machine requires a more efficient maintenance policy.
Downtime, Maintenance Crew, Life Cycle Cost, Sustaining Cost, Acquisition Cost, Cost of Unreliability 


\section{Pendahuluan}

Perkembangan teknologi yang semakin canggih membuat berbagai perusahaan di dunia yang memanfaatkan teknologi dari mesin untuk melakukan proses produksinya agar dapat menghemat waktu pengerjaan, termasuk PT XYZ. PT XYZ merupakan salah satu perusahaan yang memproduksi obat-obatan serta makanan seperti permen yang menggunakan mesin dalam proses produksinya agar dapat memenuhi permintaan konsumen.

Dalam menjalankan proses produksi, mesin memiliki keandalan (reliability), yaitu peluang keberhasilan operasi atau kinerja sistem dan peralatan yang terkait, dengan risiko minimum kehilangan, bencana atau kegagalan dari sistem tersebut [1]. Hal yang perlu dilakukan untuk menjaga kondisi sistem atau mesin ini agar tetap baik adalah peningkatan kemampuan dalam hal perawatan [2]. Perawatan (maintenance) yaitu tindakan yang dilakukan untuk mempertahankan, atau mengembalikan suatu item kepada keadaan di mana item tersebut dapat melakukan fungsinya [3].

PT XYZ telah menerapkan maintenance yang terdiri dari corrective maintenance dan preventive maintenance pada mesin-mesinnya. Corrective maintenance dilakukan saat mesin mengalami kerusakan, sedangkan preventive maintenance dilakukan pada setiap hari oleh operator, serta perawatan mingguan, bulanan dan tahunan oleh maintenance crew. Perusahaan ini telah melakukan penilaian kondisi mesin berdasarkan availability yang ditargetkan setiap tahunnya. Menurut [1], availability adalah kemampuan suatu item agar dapat digunakan pada selang waktu tertentu. PT XYZ menghitung pencapaian dari setiap mesin terhadap targetnya. Selain itu, perusahaan ini juga telah menerapkan pendataan frekuensi downtime yang terjadi pada mesin. Tabel I berikut adalah rekap data mesin Eurosicma yang digunakan pada proses packaging pada periode Januari 2017 - Oktober 2017

Tabel I

Rekap Data Mesin Eurosicma Periode Januari - Oktober 2017

\begin{tabular}{ccrcc}
\hline No. & Nama Mesin & $\begin{array}{c}\text { Target } \\
\text { Availability } \\
\text { tiap Bulan } \\
(\%)\end{array}$ & $\begin{array}{c}\text { Frekuensi } \\
\text { Availability } \\
\text { mencapai } \\
\text { target (Bulan) }\end{array}$ & $\begin{array}{c}\text { Frekuensi } \\
\text { Downtime }\end{array}$ \\
\hline 1 & EUROSICMA E75 DS (4) / A & $100.00 \%$ & 1 & 37 \\
2 & EUROSICMA E75 DS (6) / B & $99.90 \%$ & 1 & 33 \\
3 & EUROSICMA E75 DS (10)/ C & $100.00 \%$ & 2 & 22 \\
4 & EUROSICMA E80 DS (1) / A & $100.00 \%$ & 2 & 12 \\
5 & EUROSICMA E80 DS (2) / B & $99.20 \%$ & 3 & 27 \\
6 & EUROSICMA E80 DS (3) / C & $99.90 \%$ & 1 & 26 \\
7 & EUROSICMA E80 DS (5) / D & $0 \%$ & 0 & 0 \\
8 & EUROSICMA E80 DS (7) / E & $99.20 \%$ & 4 & 33 \\
9 & EUROSICMA E80 DS (8) / F & $96.80 \%$ & 8 & 15 \\
10 & EUROSICMA E80 DS (9) / G & $100.00 \%$ & 1 & 26 \\
\hline
\end{tabular}

Berdasarkan Tabel 1, mesin Eurosicma E80 DS (5)/D memiliki nilai 0 karena tidak digunakan pada tahun 2017. Mesin yang paling sedikit mencapai target availability-nya adalah mesin Eurosicma E75 DS (4)/A, Eurosicma E75 DS (6)/B, Eurosicma E80 DS (3)/C dan Eurosicma E80 DS (9)/G dengan frekuensi sebanyak 1 bulan pada tahun 2017. Kemudian diantara ke empat mesin tersebut dilihat yang memiliki frekuensi downtime tertinggi, yaitu mesin Eurosicma DS (4)/A sebanyak 37 kerusakan. Oleh karena itu, mesin ini dipilih untuk menjadi objek penelitian.
Mesin Eurosicma E75 DS (4)/A telah digunakan selama lebih dari 24 tahun, sehingga ada kemungkinan sering mengalami kerusakan dikarenakan masa penggunaan melampaui umur optimalnya. Suatu perusahaan perlu untuk mengetahui umur optimal dari penggunaan mesinnya agar mesin dapat berfungsi dengan baik dan mengurangi kegiatan perbaikan. Selain itu, ketersediaan maintenance crew yang optimal juga perlu diketahui perusahaan agar saat mesin rusak, mesin dapat langsung diperbaiki. Pada [4] telah dilakukan penelitian untuk mengetahui umur komponen Base Transceiver Station dan jumlah maintenance crew yang optimal dengan menggunakan metode Life Cycle Cost (LCC). Life Cycle Cost (LCC) adalah suatu jumlah semua biaya yang dikeluarkan dari suatu item dalam rentang waktu tertentu [5]. Nilai LCC terendah komponen BTS yang diperoleh dari [4] adalah IDR 168.960.292 dengan umur optimal selama tiga tahun dengan maintenance crew sebanyak satu orang. Metode yang serupa juga telah digunakan pada [6] untuk mesin plastic injection dengan nilai LCC terendah Rp5.287.581.342 untuk umur mesin optimal selama 10 tahun dengan maintenance crew sebanyak 1 orang dan mesin spinning manual selama 3 tahun dengan 1 orang maintenance crew berdasarkan nilai LCC terkecil Rp1.434.002.591,21.

Kerusakan pada mesin saat proses produksi menyebabkan perusahaan terhambat dalam menghasilkan produk. Hal ini dapat mengakibatkan adanya pendapatan yang hilang bagi perusahaan karena mesin tidak bisa digunakan. Oleh karena itu, dilakukan perhitungan money lost pada PT XYZ. Pada [7], [8] dijelaskan bahwa untuk menghitung money lost dapat dilakukan dengan menggunakan metode Cost of Unreliability (COUR) yang terdiri dari corrective money lost dan downtime money lost. Pada [7] diperoleh corrective money lost sebesar \$2,340,421.98 dan $\$ 2,380,687.64$ berdasarkan downtime pada objek Base Transceiver Station, sedangkan [8] memperoleh output corrective money lost sama dengan downtime money lost senilai Rp601.498.283 pada Ladle Turret, Rp 429.239.800 pada Tundish Car, Rp1.540.278.169 pada Mould, Rp1.272.144.510 pada Segment, dan Rp1.148.393.244 pada TCM.

\section{Studi literatur}

\subsection{Maintenance}

Maintenance didefinisikan sebagai tindakan yang dilakukan untuk mempertahankan, atau mengembalikan suatu item agar kembali kepada keadaan item itu dapat melakukan fungsinya [3]. Maintenance terbagi atas dua, yaitu preventive dan corrective maintenance. Preventive maintenance adalah suatu tindakan perawatan yang dilakukan selama interval tertentu untuk mencegah peluang terjadinya suatu kegagalan fungsi dari sebuah peralatan sedangkan corrective maintenance didefinisikan sebagai tindakan perbaikan yang tidak terjadwal karena dilakukan pada saat ditemukannya kegagalan fungsi dari peralatan, sehingga harus diperbaiki agar dapat digunakan kembali sebagaimana fungsinya [9].

\subsection{Pola Kerusakan}

Rata-rata kerusakan yang terjadi pada suatu item dapat mengikuti pola kerusakan/ Bathub Curve [4]. Gambar 1 
menampilkan bathup curve pola kerusakan dimana sumbu X menyatakan waktu kerusakan yang dapat didefenisikan dalam menit, hari, dan lain-lain, sedangkan Sumbu-Y menunjukkan laju kerusakan yang didefenisikan dalam kerusakan per unit waktu.

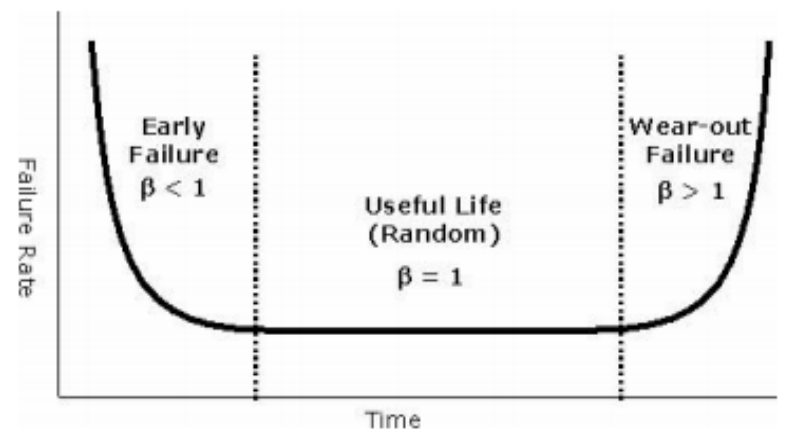

Gambar 1 Bathup Curve

Gambar 1 menunjukkan pola kerusakan suatu item Berdasarkan Gambar 1, terdapat tiga fase pola kerusakan suatu item, diantaranya fase early failure, fase useful life, dan fase wear-out life [4]. Pada fase early failure, laju kerusakan yang tinggi terjadi karena adanya masa adaptasi dari suatu item. Seiring berjalannya waktu setelah pemakaian item, laju kerusakannya akan menurun. Pada fase ini, terdapat fungsi kepadatan probabilitas Weibull yang bernilai $\beta<1$. Pada fase useful life laju kerusakan yang terjadi konstan seiring berjalannya waktu. Fase ini dapat dikatakan fase normal dan memiliki fungsi kepadatan probabilitas Weibull dan Eksponensial yang bernilai $\beta=1$. Pada fase wear-out life laju kerusakan pada suatu item meningkat seiring berjalannya waktu setelah pemakaian, sehingga memiliki nilai fungsi kepadatan probabilitas Weibull dan Normal sebesar $\beta>1$.

\subsection{Risk Matrix}

Risk matrix menurut [10] adalah salah satu teori yang digunakan dalam pemilihan suatu kondisi dengan melihat risiko yang ada di dalamnya. Risk Matrix ditampikan dalam bentuk tabel yang terdiri dari kombinasi penilaian severity/consequences dan likelihood [10].

\subsection{Life Cycle Cost (LCC)}

Life Cycle Cost (LCC) adalah suatu jumlah semua biaya yang dikeluarkan dari suatu item dalam rentang waktu tertentu [5]. Pada [4] dijelaskan bahwa Life Cycle Cost (LCC) adalah total jumlah perkiraan biaya yang dikeluarkan saat suatu equipment atau proyek dioperasikan dari awal hingga selesai. Menurut [11], model LCC digambarkan pada Gambar 2. Berdasarkan Gambar 2, diketahui bahwa Life Cycle Cost terdiri atas Sustaining Cost dan Acquisition Cost. Nilai LCC dan Sustaining cost diperoleh dari rumus berikut [11].

$\mathrm{LCC}=$ Sustaining Cost + Acquisition Cost

Sustaining Cost $=O C+M C+S C$

Acquisition Cost $=P C+P o p C$

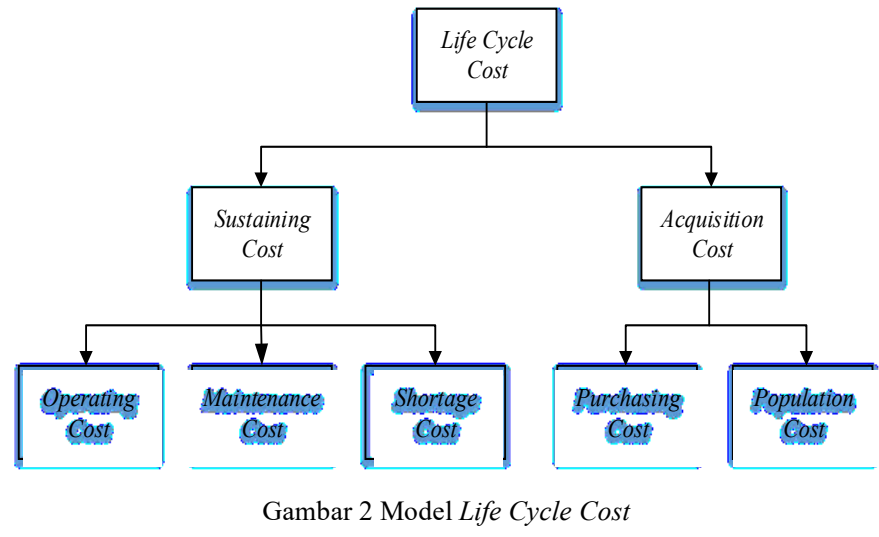

$\mathrm{OC}=\mathrm{EC}+(\mathrm{TK} \times \mathrm{Upah}) \times 12$

dengan keterangan:

EC : Energy cost

TK : Jumlah Tenaga Kerja

$\mathrm{MC}=\mathrm{Cr}+(\mathrm{CL} \times \mathrm{M})+\mathrm{Cc}+\mathrm{Ce}$

dengan keterangan:

$\mathrm{Cr}$ : Repair/replace cost

CL : Labor Repair Cost

Cc : Consumable Cost

Ce : Equipment Cost

$\mathrm{M}:$ Maintenance Crew

$\mathrm{SC}=\mathrm{Cs}[\mathrm{E}(\mathrm{S})]$

dengan keterangan:

Cs : Shortage Cost per unit

$\mathrm{E}(\mathrm{S})$ : Expected number of units short

$\mathrm{E}(\mathrm{S})=\sum(\mathrm{n}=0)^{\wedge} \mathrm{NnPn}$

dengan keterangan:

$\mathrm{N}$ : Jumlah unit

$n$ : Jumlah defective units

Pn : Probability damaged machine

Lebih lanjut, pada perhitungan purchasing cost, nilai annual purchasing cost berbeda pada setiap retirement agenya [11]. Perhitungan annual purchasing cost melibatkan suku bunga untuk kredit. Selain itu, population cost dihitung dari perkalian antara annual equivalent cost dengan jumlah populasi unit perangkatnya [11]. Equivalent cost didapatkan dari selisih antara purchasing cost dengan book value. Perhitungan book value menurut [4] adalah sebagai berikut:

Annual purchasing cost $=\mathrm{P}(\mathrm{A} \mid \mathrm{P}, \mathrm{i}, \mathrm{n}) \times \mathrm{N}$

$(\mathrm{A} \mid \mathrm{P}, \mathrm{i}, \mathrm{n})$ : Equal Payment Series Capital Recovery

$\mathrm{N} \quad$ : Jumlah unit

Book value $=\mathrm{P}-\mathrm{n}(\mathrm{P}-\mathrm{F}) / \mathrm{L}$

$\mathrm{P}$ : Biaya pertama kali pembelian unit

$\mathrm{n}$ : Retirement age of units $\mathrm{n}>1$

$\mathrm{F}$ : Estimasi salvage value pada unit

L : Estimated life of the unit 


\subsection{Cost of Unreliability (COUR)}

Cost of Unreliability (COUR) merupakan biaya yang ditimbulkan karena adanya kegagalan reliabilitas, termasuk biaya kegiatan perawatan yang buruk [12]. Perhitungan COUR dapat dilakukan dalam beberapa tahapan. Tahap pertama adalah menghitung failure rate mesin yang diperoleh dari data kerusakan mesin, kemudian melakukan perhitungan time lost yang disebabkan oleh waktu repair dan downtime mesin, lalu menghitung money lost yang akan terjadi dikarenakan unreliability dari mesin tersebut [13]. Menurut [7] dan [8] dan nilai money lost terdiri dari corrective money lost yang dihitung dengan data Mean Time To Repair (MTTR) dan downtime money lost yang dihitung dengan nilai Mean Downtime (MDT).

\section{Metode Penelitian}

Metodologi penelitian dapat dilihat pada Gambar 3. Berdasarkan Gambar 3, hal yang dilakukan pertama kalinya adalah menghitung nilai MTTR dan MTTF dari data keseluruhan mesin Eurosicma E75 DS (4)/A. Selain itu, juga dilakukan pemilihan subsistem kritis dan komponen kritis, kemudian dilakukan perhitungan MTTF, MTTR, dan MDT dari data yang ada di komponen kritis yang nantinya akan digunakan untuk perhitungan metode COUR.

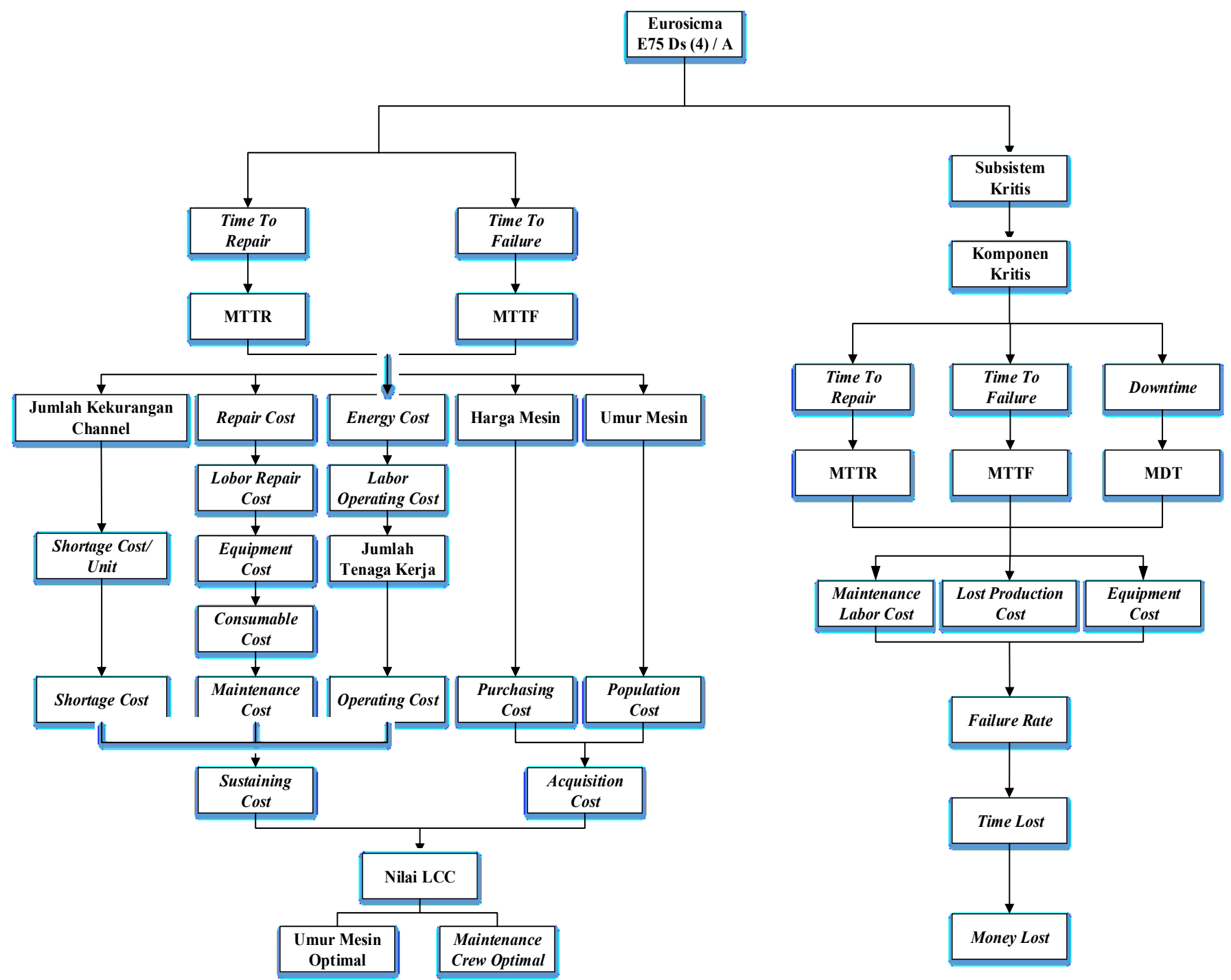

Gambar 3 Metodologi Penelitian

Kemudian data energy cost, repair cost, jumlah kekurangan channel, umur mesin, harga mesin, labor operating cost, labor repair cost, jumlah tenaga kerja, equipment cost, dan shortage cost/unit digunakan untuk menghitung komponen biaya yaitu operating cost, maintenance cost, shortage cost yang digunakan untuk menghitung sustaining cost dan komponen purchasing cost, dan population cost untuk menghitung acquisition cost. Selanjutnya akah dilakukan penjumlahan antara sustaining cost dan acquisition cost untuk mendapatkan nilai LCC. Nilai LCC yang diperhatikan adalah yang paling kecil untuk menganalisis umur mesin dan jumlah maintenance crew yang optimal. Sedangkan perhitungan metode Cost of Unreliability dilakukan dengan melakukan perhitungan menggunakan data maintenance labor cost, lost production cost, dan equipment cost untuk menghitung failure rate, time lost, dan menghasikan output berupa money lost. 


\section{4. hasil dan analisis}

\subsection{Pemilihan Subsistem dan Komponen Kritis Mesin}

Mesin Eurosicma E75 DS (4)/A memiliki tiga subsistem yaitu subsistem elektrik, subsistem pneumatik, dan subsistem mekanik. Berdasarkan tiga subsistem ini, dilakukan pemilihan subsistem yang dinilai memiliki risiko paling tinggi dalam penyebab kegagalan fungsi mesin. Pemilihan ini dilakukan dengan menggunakan risk matrix. Risk matrix merupakan penggabungan dua penilaian yaitu severity dan likelihood. Severity melihat konsekuensi yang terjadi karena kerusakan yang terjadi pada subsistem atau komponen, sedangkan likelihood memperhatikan frekuensi terjadinya kerusakan tersebut. Hasil risk matrix pemilihan subsistem dapat dilihat pada Tabel 2 berikut. Berdasarkan Tabel 2, subsistem yang berada pada daerah yang lebih gelap adalah subsistem yang dinilai lebih kritis karena memiliki penilaian terbesar dari severity dan likelihood matrix. Oleh karena itu, subsistem mekanik adalah subsistem yang memiliki risiko yang lebih tinggi dan terpilih untuk diteliti secara lebih mendalam. Setelah itu, dilanjutkan dengan pemilihan komponen kritis dari subsistem yang terpilih. Subsistem yang terpilih adalah mekanik. Subsistem ini memiliki delapan komponen diantaranya adalah Hopper, Feeding Disk, Motorized Brush, Roller, Reel, Cylinder, Cross Jaws, dan Main Motor. Pemilihan komponen kritis dilakukan dengan cara yang sama dengan pemilihan subsistem kritis, yaitu menggunakan risk matrix. Hasil penilaian risk matrix komponen dapat dilihat pada Tabel 3. Berdasarkan Tabel 3, komponen yang terpilih untuk diamati lebih lanjut adalah Cross Jaws, Cylinder, dan Main Motor karena terletak pada daerah yang lebih gelap yang menandakan komponen tersebut memiliki penilaian yang lebih besar dibandingkan yang lainnya. Oleh karena itu, ketiga komponen ini akan diteliti dalam perhitungan Cost of Unreliability.

Tabel 2

Risk Matrix Subsistem

\begin{tabular}{c|ccccc}
\hline & \multicolumn{5}{|c}{ Severity } \\
\cline { 2 - 5 } & Subsistem & $\begin{array}{c}\text { Minor } \\
(1)\end{array}$ & $\begin{array}{c}\text { Major } \\
(2)\end{array}$ & $\begin{array}{c}\text { Hazardous } \\
(3)\end{array}$ & $\begin{array}{c}\text { Critical } \\
(4)\end{array}$ \\
\hline & Almost & & Mekanik & \\
Certaint (5) & & & & \\
Likely (4) & & & & \\
Possible (3) & & Elektrik & \\
Unlikely (2) & & Pneumatik & \\
Rare (1) & & & \\
\hline
\end{tabular}

Tabel 3

Risk Matrix Subsistem

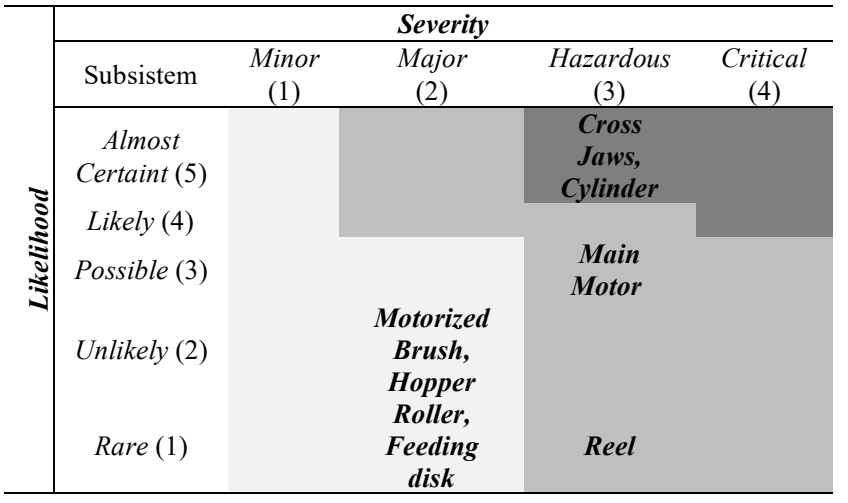

Berdasarkan Tabel 3, komponen yang terpilih untuk diamati lebih lanjut adalah Cross Jaws, Cylinder, dan Main Motor karena terletak pada daerah yang lebih gelap yang menandakan komponen tersebut memiliki penilaian yang lebih besar dibandingkan yang lainnya. Oleh karena itu, ketiga komponen ini akan diteliti dalam perhitungan Cost of Unreliability.

\subsection{Penentuan Distribusi yang Mewakili pada Mesin dan Komponen Kritis}

Penentuan distribusi dari data TTF, TTR, dan DT pada mesin dan komponen kritis dilakukan dengan menggunakan software Minitab 17. Tabel 4 menunjukkan hasil distribusi yang mewakili masing-masing data pada mesin dan komponen kritis. Distribusi yang terpilih adalah yang memiliki nilai Anderson Darling (AD) terkecil dan nilai PValue yang lebih besar dari $\alpha$.

Tabel 4

Tabel Uji Distribusi

\begin{tabular}{cccc}
\hline Nama Mesin & Time To Repair & Time To Failure & Downtime \\
\hline $\begin{array}{c}\text { Eurosicma E75 } \\
\text { DS (4)/A }\end{array}$ & Weibull & Weibull & - \\
\hline Nama & Time To Repair & Time To Failure & Downtime \\
Komponen & & & \\
\hline Cross Jaws & Weibull & Weibull & Weibull \\
Cylinder & Weibull & Weibull & Weibull \\
Main Motor & Normal & Weibull & Normal \\
\hline
\end{tabular}

\subsection{Penentuan Parameter Keandalan TTR, TTF dan DT}

Penentuan parameter keandalan ini dilakukan berdasarkan distribusi yang telah terpilih sebelumnya. Ada dua jenis distribusi yang terpilih diantara mesin dan semua komponen, yaitu distribusi Weibull dan Normal. Untuk menghitung parameternya menggunaka distribusi Normal adalah menggunakan nilai $\mu$ sebagai parameter, sedangkan pada distribusi Weibull, parameter yang digunakan adalah $\mu$ dan $\beta$ kemudian dihitung menggunakan rumus $\eta$. $\Gamma(1+1 / \beta)$ dimana lambang $\Gamma$ menunjukkaan Tabel Gamma. Perhitungan parameter keandalan mesin Eurosicma E75 DS (4)/A beserta komponen kritisnya dapat dilihat pada Tabel 5 berikut.

Tabel 5

Nilai MTTR, MTTF dan MDT

\begin{tabular}{cccc}
\hline Nama Mesin & $\begin{array}{c}\text { Mean Time To } \\
\text { Repair }\end{array}$ & $\begin{array}{c}\text { Mean Time To } \\
\text { Failure }\end{array}$ & $\begin{array}{c}\text { Mean } \\
\text { Downtime }\end{array}$ \\
\hline Eurosicma E75 & 127,28 & 367,36 & - \\
DS (4)/A & Mean Time To & Mean Time To & Mean \\
Repair & Failure & Downtime \\
\hline Nama Komponen & 98,74 & 1724,63 & 108,18 \\
& 79,45 & 3202,13 & 78,15 \\
Cross Jaws & 92,15 & 1329,68 & 98,33 \\
Cylinder & & & \\
\hline
\end{tabular}

\subsection{Perhitungan Life Cycle Cost (LCC)}

Perhitugann Life Cycle Cost (LCC) dilakukan dengan penjumlahan antara sustaining cost dengan acquisition cost. Sustaining cost merupakan biaya yang harus dikeluarkan atas kepemilikan suatu item dalam waktu tertentu, sedangkan acquisition cost adalah biaya yang dikeluarkan pada saatu suatu mesin/sistem dibeli [4]. Setelah dilakukan perhitungan, 
diperoleh hasil dalam grafik Life Cycle Cost (LCC) seperti pada Gambar 3.

Biaya LCC dihitung dengan kondisi $\mathrm{M}=1$ berarti sebanyak 1 orang, $\mathrm{M}=2$ sebanyak 2 orang, sampai dengan $\mathrm{M}=8$ sebanyak 8 orang, sedangkan $\mathrm{n}$ menandakan jumlah tahun penggunaan mesin. Berdasarkan Gambar 4, diketahui bahwa nilai LCC terkecil yang diperoleh adalah sebesar
Rp1.451.140.737 dengan $M=7$ yang berarti jumlah maintenance crew optimal sebanyak 7 orang dan retirement age optimal adalah selama 8 tahun. Penggunaan mesin yang melewati umur optimalnya akan memperbesar nilai Life Cycle Cost karena nilai maintenance cost yang juga meningkat. Peningkatan maintenance cost ini dikarenakan mesin sering mengalami gangguan saat dioperasikan.

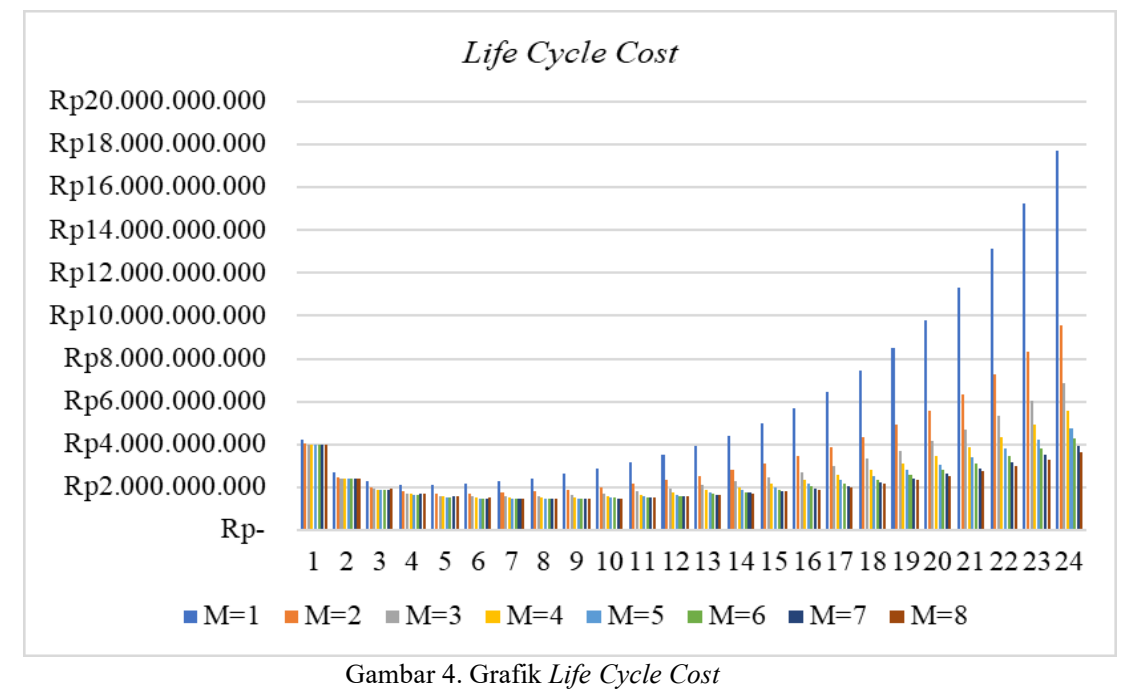

\subsection{Perhitungan Cost of Unreliability (COUR)}

Perhitungan COUR dilakukan dengan cara menghitung failure rate, time lost, dan money lost [5]. Perhitungan failure rate dapat dilihat pada Tabel 6 berikut. Berdasarkan Tabel 6, didapatkan dengan cara 1/MTTF (jam). Nilai MTTF pada penelitian ini didapatkan dari data tahun 2013 - 2017. Setelah itu dilakukan perhitungan time lost yang terbagi atas dua, corrective lost time dan downtime lost time. Perbedaan antara kedua time lost ini adalah corrective lost time menggunakan corrective time/failure (MTTR) setiap komponen, sedangkan downtime lost time membutuhkan data downtime/failure (MDT). Tabel 7 menunjukkan perhitungan corrective lost time, sedangkan untuk perhitungan downtime ditunjukkan pada Tabel 8.

Tahap terakhir dalam perhitungan Cost of Unreliability (COUR) adalah menghitung money lost yang terdiri atas dua jenis yaitu corrective COUR dan downtime COUR. Hasil perhitungan keduanya ditunjukkan pada Tabel IX dan Tabel X. Berdasarkan Tabel IX dan Tabel X, dilakukan perhitungan total corrective COUR dan total downtime COUR seperti pada Tabel XI berikut.

Tabel 6

Perhitungan Failure Rate

\begin{tabular}{cccc}
\hline \multirow{2}{*}{ Failure Rate } & \multicolumn{3}{c}{ Komponen Kritis } \\
\cline { 2 - 4 } & Cross Jaw & Cylinder & Main Motor \\
\hline Study Interval & 37440 & 37440 & 37440 \\
Number of & 31 & 18 & 28 \\
Failures & 1724,63 & 3202,133697 & 1329,68 \\
MTTF (jam) & 0,000579835 & 0,000312 & 0,0007521 \\
Failure Rate & & & \\
\hline
\end{tabular}

Tabel 7

Perhitungan Corrective Lost Time

\begin{tabular}{cccc}
\hline \multirow{2}{*}{ Time Lost } & \multicolumn{3}{c}{ Komponen Kritis } \\
\cline { 2 - 4 } Cross Jaw & Cylinder & Main Motor \\
\hline $\begin{array}{c}\text { Failure Rate } \\
\text { Number of } \\
\text { Failures }\end{array}$ & 0,000579835 & 0,000312 & 0,000752059 \\
$\begin{array}{c}\text { Corrective Time/ } \\
\text { Failure (MTTR) } \\
\text { Corrective Lost } \\
\text { Time Hours/5 } \\
\text { Years }\end{array}$ & 31 & 18 & 28 \\
\hline
\end{tabular}

Tabel 8

Perhitungan Downtime Lost Time

\begin{tabular}{cccc}
\hline Time Lost & \multicolumn{3}{c}{ Komponen Kritis } \\
\cline { 2 - 4 } Cross Jaw & Cylinder & Main Motor \\
\hline $\begin{array}{c}\text { Failure Rate } \\
\text { Number of } \\
\text { Failures }\end{array}$ & 0,000579835 & 0,000312292 & 0,000752059 \\
$\begin{array}{c}\text { Downtime/ Failure } \\
\text { (MDT) }\end{array}$ & 31 & 18 & 28 \\
$\begin{array}{c}\text { Downtime Lost } \\
\text { Time Hours/5 } \\
\text { Years }\end{array}$ & 108,18 & 78,15 & 98,33 \\
\hline
\end{tabular}

Berdasarkan hasil perhitungan pada Tabel XI, maka diketahui bahwa nilai downtime COUR lebih besar dari pada nilai corrective COUR, hal ini berarti mesin Eurosicma E75 DS (4)/A belum mampu bekerja secara efektif dan membutuhkan kebijakan perawatan yang lebih efisien.

\section{Kesimpulan}

Perhitungan Life Cycle Cost (LCC) dilakukan untuk mendapatkan nilai Life Cycle Cost, umur mesin dan jumlah 
maintenance crew yang optimal. Berdasarkan perhitungan, diperoleh nilai LCC terkecil adalah sebesar Rp1.451.140.737 dengan umur optimal penggunaan mesin adalah selama delapan tahun dan jumlah maintenance crew yang disediakan sebanyak tujuh orang. Hal ini berarti mesin telah melampaui batas umur optimalnya yang digunakan selama 24 tahun. Selain itu jumlah money lost yang dihitung menggunakan metode Cost of Unreliability (COUR) adalah senilai Rp57.097.869.694 untuk corrective money lost, dan Rp60.671.980.382 untuk downtime money lost. Hal ini berarti bahwa perusahaan kehilangan pendapatan sebanyak Rp57.097.869.694 dikarenakan perbaikan mesin, dan senilai Rp60.671.980.382 saat mesin mengalami downtime dan tidak bisa digunakan. Kondisi ini menandakan mesin membutuhkan kebijakan perawatan yang lebih efisien.

Tabel 9

Perhitungan Corrective COUR

\begin{tabular}{cccc}
\hline Money Lost & Cross Jaw & Komponen Kritis & \\
\cline { 2 - 4 } & & & Main Motor \\
\hline $\begin{array}{c}\text { Corrective } \\
\text { Lost Time } \\
\text { Hours } / 5 \text { Years }\end{array}$ & 3060,810588 & 1430,018784 & 2580,0992 \\
$\begin{array}{c}\text { Lost Profit } \\
\text { (Rp) }\end{array}$ & 24.241 .619 .855 & 11.325 .748 .771 & 20.434 .385 .664 \\
$\begin{array}{c}\text { Labor } \\
\text { Maintenance } \\
\text { Cost (Rp) } \\
\text { Corrective }\end{array}$ & 7.421 .485 & 3.467 .337 & \\
COUR (Rp) & 24.716 .098 .079 & 11.547 .426 .250 & 20.834 .345 .365 \\
\hline
\end{tabular}

Tabel 10

PerHitungan Downtime COUR

\begin{tabular}{|c|c|c|c|}
\hline \multirow{2}{*}{ Money Lost } & \multicolumn{3}{|c|}{ Komponen Kritis } \\
\hline & Cross Jaw & Cylinder & Main Motor \\
\hline \multicolumn{4}{|l|}{ Downtime } \\
\hline $\begin{array}{c}\text { Lost Time } \\
\text { Hours } / 5 \\
\text { Years }\end{array}$ & 3353,587213 & 1406,672744 & 2753,282 \\
\hline $\begin{array}{l}\text { Lost Profit } \\
\quad(\mathrm{Rp})\end{array}$ & 26.560 .410 .730 & 11.140 .848 .129 & 21.805 .993 .440 \\
\hline \multicolumn{4}{|l|}{ Equipment/ } \\
\hline $\begin{array}{l}\text { Spare Part } \\
\text { Cost (Rp) }\end{array}$ & 511.732 .257 & 214.647 .711 & 420.130 .184 \\
\hline Labor & & & \\
\hline $\begin{array}{c}\text { Maintenance } \\
\text { Cost }(\mathrm{Rp})\end{array}$ & 8.131 .374 & 3.410 .731 & 6.675 .826 \\
\hline $\begin{array}{l}\text { Downtime } \\
\text { COUR (Rp) }\end{array}$ & 27.080 .274 .361 & 11.358 .906 .571 & 22.232 .799 .450 \\
\hline
\end{tabular}

Tabel XI

Total Corrective COUR dan Downtime COUR

\begin{tabular}{cc}
\hline Jenis Biaya & Jumlah (Rp) \\
\hline Corrective COUR & 57.097 .869 .694 \\
Downtime COUR & 60.671 .980 .382 \\
\hline
\end{tabular}

\section{Referensi}

[1] R. F. Stapelberg, Handbook of Reliability, Availability, Maintainability, and Safety in Engineering Design. London: Springer, 2009.

[2] J. Heizer dan B. Render, Operations Management. Upper Saddle River, New Jersey: Pearson Education, Inc., 2011.

[3] C. Ebelling, An Introduction To Reliability and Maintainability
Engineering. Singapore: McGraw-Hill, 1997.

[4] J. Alhilman, R. R. Saedudin, F. T. D. Atmaji, dan A. G Suryabrata, "LCC application for estimating total maintenance crew and optimal age of BTS component," 2015 3rd Int. Conf. Inf. Commun. Technol. ICoICT 2015, hal. 543-547, 2015.

[5] B. S. Dhillon, Life Cycle Costing For Engineers. Boca Raton: CRC Press, 2010.

[6] A. R. Eliyus dan J. Alhilman, "Estimasi Biaya Maintenance yang Optimal dengan Metode Markov Chain dan Penentuan Umur Mesin serta Jumlah Maintenance Crew yang Optimal dengan metode Life Cycle Cost (Studi Kasus: PT TOA GALVA)," J. Rekayasa Sist. Ind., vol. 1, no. 2, hal. 48-54, 2014.

[7] V. S. Asih, R. R. Saedudin, dan A. Kurniawati, "Performance Assesment Berbasis Reliability pada Base Transceiver Station (BTS) Menggunakan Metode Reliability Availability Maintainability Analysis dan Cost of Unreliability (COUR) ( Studi Kasus : Base Transceiver Station (BTS) - PT . Telkomsel Bandung," e-Proceeding Eng., vol. 2, no. 2, hal. 4984-4991, 2015.

[8] I. Praesita, J. Alhilman, F. R. Industri, U. Telkom, K. P. Indicator, dan R. B. Diagram, "Penilaian Kinerja Berbasis Reliability pada Continuous Casting Machine 3 (CCM 3) PT Krakatau Steel (Persero) Tbk Menggunakan Metode Reliability Availability MAintainability dan Cost of Unreliability," $J$. Rekayasa Sist. Ind., vol. 4, no. 2, hal. 2884-2891, 2017.

[9] A. C. Marquez, The Maintenance Management Framework: Models and Methods for Complex Systems Maintenance. London: Springer, 2007.

[10] D. Ristić, "a Tool for Risk Assessment," Saf. Eng. J., vol. 3, no. 3, hal. 121-127, 2013.

[11] A. Anggriawan dan A. Kurniawati, "Biaya Maintenance Dengan (Studi Kasus : Pt Telkomsel Indonesia)," J. Rekayasa Sist. Ind., vol. 2, no. 3, hal. 33-38, 2015.

[12] F. Vicente, "Assessing the cost of unreliability in gas plant to have a sustainable operation," Pet. Chem. Ind. Conf. Eur. Conf. Proceedings, PCIC Eur., 2012.

[13] J. Alhilman, "Cost of unreliability method to estimate loss of revenue based on unreliability data: Case study of Printing Company," IOP Conf. Ser. Mater. Sci. Eng., vol. 277, no. 1, 2017. 